\title{
MATHEMATICS AND PLAUSIBLE REASONING
}

\author{
By GEORGE POLYA
}

A two-volume guide to the practical art of plausible reasoning by the famous author of How to Solve It. Professor Polya uses mathematics to show how hunches and guesses play an important part in even the most rigorously deductive sciences.

Volume I. INDUCTIONS AND ANALOGY IN MATHEMATICS 336 pages $\$ 6$ Volume II. PATTERNS OF PLAUSIBLE INFERENCE 240 pages \$ 5 The set $\$$ IO

Order from your bookstore, or

PRINCETON UNIVERSITY PRESS

Princeton, New Jersey

\section{THE BRITISH JOURNAL FOR THE PHILOSOPHY OF SCIENCE}

\section{Contents of the August issue 1954}

Articles

LIVING AND Lifeless MAGHines ...... R. C. Kapp

Logic And Existence . . . . . . . . Czeslaw Lejewski

Analysis of Projection ......... J. R. Smythies

On Variables in Mathematics and

Natural Science . . . . . . . . Karl Menger

Notes and Comments
A Note on Degree of Confirmation.. K. R. Popper
A Note on A Suggested Modification to Reconcil Newton's Corpuscular THEORY OF LIGHT WITH FOUGAULT'S
EXPERIMENT OF $1850 \ldots$ A. I. Sabra
E. A. Milne's Scales of Time ..... G. J. Whitrow

\section{THOMAS NELSON \& SONS LTD. \\ Parkside Works, Edinburgh 9}




\section{A BIBLIOGRAPHY OF SYMBOLIC LOGIC \\ By ALONZO CHURCH}

A complete bibliography of symbolic logic covering the period 1666-1935, indexed by authors and by subjects, as it appeared in The Journal of SYMBOLIC Logic, vol. 1, pp. 121-218, and vol. 3. pp. 178-212. On sale, in unbound form only, at $\$ 3.25$. The two parts are also on sale separately at $\$ 2.00$ for the fisst part and $\$ 1.25$ for the second part.

A continuation of the bibliography from Januari 1, 1936, is provided by reviews appearing in THE JOURNAL OF SYMBOLIC LOGic. These reviews, which are indexed by authors biennially and by subjects at longer intervals, are designed to cover current literature in this field completely, including both books and articles in periodicals.

Orders for the Bibliography, and for the Journal, should be addressed to the Secretary-Treasurer of the Association for Symbolic Logic, Rutgers University, New Brunswick, New Jersey.

\section{Scripta Mathematica Publications}

1. Scripta Mathematica is a quarterly journal devoted to the history and philosophy of mathematics. Subscription $\$ 3.00$ per year.

2. Scripta Mathematica Library. Vol. I. Poetry of Mathematics and Other Essays, by David Eugene Smith. Vol. II. Mathematics and the Question of Cosmic Mind, by Cassius Jackson Keyser. Vol. III. Scripta Mathematica Forum Lectures. Vol. IV. Fabre and Mathematics and Other Essays, by Lao G. Simons. Price of each volume, in a beautiful silverstamped cloth binding, \$1.00. Vol. V. Galois Lectures. Price \$1.25.

3. Portraits of Eminent Mathematicians, Philosophers, and Physicists, with Their Biographies. Portfolio I ( 13 folders), out of print. Portfolio II (14 folders). \$3.75. Portfolio III ( 13 folders). \$3.75. Portfolio IV (13 folders). \$3.75.

4. Visual Aids in the Teaching of Mathematics. Single portraits, mathematical themes in design, interesting curves, and other pictorial items. Suitable for framing and for inclusion in students' notebooks. List on request.

5. George Peacock's Treatise on Algebra. (Reprint) two volumes. \$6.50.

Scripta Mathematica, Yeshiva College Amsterdam Avenue \& 186 St., New York Gity 